\title{
EDUCAÇÃO À DISTÂNCIA QUE TRANSCENDE A PLATAFORMA: RELAÇÕES MAIS HUMANAS EM EXPERIÊNCIAS REAIS E SIGNIFICATIVAS
}

\author{
SÃO BERNARDO DO CAMPO/SP JULHO/2018
}

\author{
Adriana de Jesus Ribeiro - SENAC - adriana.jribeiro@sp.senac.br \\ Regina Fujiko Tagava - SENAC - reginaft@sp.senac.br \\ Valéria Seixas Fraga - SENAC - valeria.sfraga@sp.senac.br \\ Fabiana Vilela de Lima Moura - SENAC - fabiana.vlmoura@sp.senac.br
}

Tipo: Investigação Científica (IC)

Natureza: Planejamento de Pesquisa

Categoria: Métodos e Tecnologias

Setor Educacional: EDUCAÇÃO MÉDIA E TECNOLÓGICA, EDUCAÇÃO SUPERIOR

\begin{abstract}
RESUMO
A Educação a Distância (EAD) é um caminho sem volta por sua facilidade em integrar o aprendiz ao processo de aprendizagem em um mundo saturado de informação, conectado em rede e determinado por algoritmos, que tem seu valor comprovado para a sociedade. Pensando na melhoria contínua, questiona-se nesse trabalho como transcender a plataforma EAD para relações mais humanas em experiências reais e significativas. Nesse sentido, para compreender e responder a questão, será estudado e analisado nesse trabalhado a EAD e sua evolução diante das singularidades e experimentações do aprendizado contemporâneo, nos âmbitos individuais e coletivos por meio de revisão bibliográfica de artigos nacionais e internacionais, publicados em periódicos indexados de 2010 a 2017. O principal objetivo do estudo é discutir essa modalidade de educação na contemporaneidade de forma a fomentar o protagonismo do aluno para as novas demandas intelectuais e destacar ideias ou contrapontos relevantes, em prol das relações mais humanizadas, da aprendizagem contínua, da experiência significativa para o aluno, do incentivo à produção de conhecimento, ora em moldes presenciais, ora não, porém ressignificada perante à sociedade em rede, pós-digital e multiplataforma.
\end{abstract}

Palavras-chave: Educação à Distância, Aprendizagem Significativa, Inovação, Relações Humanas, Algoritmo. 


\section{Introdução}

Em tempos emergenciais para as transformações socioculturais, econômicas e políticas, em que o aqui (global) e o agora (real time) está além das distinções dos mundos on-line e off-line, virtuais e reais, informacionais ou de conhecimento, a sociedade passa por nova transição, que de acordo com Longo (2014), passa da era digital para a pós-digital.

Com isso, anuncia-se o paradigma social que transcende às plataformas tecnológicas e aos códigos algorítmicos do ciberespaço, afetando diretamente a produção global do conhecimento e, portanto, impactando também nas experiências de aprendizagem.

Toffler (1970) afirma que: "Os analfabetos do século XXI não serão aqueles que não conseguem ler e escrever, mas aqueles que não conseguem aprender, desaprender e reaprender". O que sugere a necessidade de repensar as metodologias e as tecnologias educacionais a fim de que se cumpram os papéis fundamentais das instituições, como o de facilitar a aprendizagem vitalícia, de inspirar a produção de conhecimento, estimular as relações humanas e inclusivas, e a de disseminar novos conceitos teóricos ou aplicações bem-sucedidas. Para tanto, será imprescindível o entendimento da sociedade em rede e do determinismo tecnológico, apontados por Castells (1999): “... a tecnologia é a sociedade, e a sociedade não pode ser entendida ou representada sem suas ferramentas tecnológicas". A arquitetura digital, apontada por Lessig (2000), é o que determinará como a vida do ciberespaço será vivida.

\section{Objetivo}

O principal objetivo do estudo é discutir da modalidade Educação a Distância - EAD na contemporaneidade de forma a fomentar o protagonismo do aluno para as novas demandas intelectuais e destacar ideias ou contrapontos relevantes, em prol das relações mais humanizadas, da aprendizagem contínua, da experiência significativa para o aluno, do incentivo à produção de conhecimento, ora em moldes presenciais, ora não, porém ressignificada perante à sociedade em rede, pós-digital e multiplataforma.

\section{Procedimento metodológico e referencial teórico}

Trata-se de pesquisa em estudo exploratório e descritivo, com revisão bibliográfica e estudo de casos.

Foram encontrados, à princípio, em 322 artigos nacionais e internacionais a partir dos descritores "educação a distância" e "aprendizagem significativa" pesquisados 
separadamente no banco de dados da Scientific Electronic Library Online - SciELO, já que em conjunto é isenta de publicação nessa base. Da quantidade de artigos encontrados apenas 3 que se aproximavam do propósito desse trabalho daqueles publicados em periódicos indexados de 2010 a 2017.

\section{A evolução da Educação a Distância - EAD}

Identifica-se na contemporaneidade a existência de diversos estudos sobre a evolução da EAD, portanto, é importante destacar que alunos e professores estão em locais diferentes enquanto aprendem e ensinam (MOORE; KEARSLEY, 2014).

É possível explorar o sentido do termo sob o ponto de vista epistemológico da palavra Teleducação que deu origem ao termo "Educação a Distância". A palavra vem do grego tele que significa "longe" ou "ao longe", que segundo Hermida (2016), pode ser compreendido como processo de ensino-aprendizagem mediado por tecnologias, em que discentes e docentes interagem espacialmente e/ou temporalmente separados, com atividades presenciais ou conectados por meio de recursos tecnológicos diversos.

Bastos, Cardoso e Sabbatini (2000) entendem que a EAD teve seu início nos cursos por correspondência no final do século XVIII por intermédio dos Correios, através do qual eram enviados materiais impressos para o desenvolvimento de diversos cursos.

Nunes (1993) destaca que a II Guerra Mundial teve uma grande importância no desenvolvimento e treinamento à distância dos soldados americanos que precisavam aprender novos conteúdos e desenvolver novas habilidades.

Já Moore \& Kearsley (2014) descrevem cinco gerações de EAD:

1. Estudos por correspondência - fundamento para a educação individualizada à distância;

2. História da transmissão por rádio e televisão - agregou dimensões orais e visuais à apresentação das informações;

3. Abordagem sistêmica pelas Universidades Abertas - integravam por áudio/ vídeo e correspondência, além da orientação presencial;

4. Teleconferência - primeira interação em tempo real de alunos e instrutores; 
5. Aulas virtuais (computador e internet) - on-line com base na internet, com métodos construtivistas de aprendizado em colaboração.

É inquestionável a evolução das tecnologias no decorrer dos tempos. Há décadas depara-se com esta avalanche de novas mídias, novos formatos de sistematização de conteúdos e informações que se multiplicam e evoluem de maneira quase vertiginosa.

Estas tecnologias crescentes nos meios de comunicação abrem oportunidades nunca imaginadas antes para o desenvolvimento da área educacional.

\section{A rejeição do algoritmo determinístico}

A presença forte de recursos tecnológicos no processo de ensino e aprendizagem, principalmente na modalidade EAD, é óbvia. Porém, o que não está claro é como os sistemas integrados e interconectados codificam e descodificam "megadados" (em sistemas de big data) de uma máquina a tantas outras. Em geral, os sistemas complexos envolvem algoritmos (códigos computacionais padronizados) fechados e que secretamente passam por um processo de data mining, que modula, defini, determina, filtra e escolhe por lógica sistêmica e estratégias mercadológicas. Um processo de clusterização de perfis, que desde a pesquisa e coleta de seus dados até a transmissão de informações e análises correlacionadas e incentivo à produção de conteúdo, busca criar mundos preditivos (cenários previsíveis) com dispositivos de produção de subjetividades e narrativas midiáticas para reforçarem a modulação do comportamento social. Em sua maioria, beneficiando interesses e interessados obscuros, em processo de manipulação da informação pelos meios de comunicação e plataformas digitais. Castells (1999, p.21), abordando a sociedade em rede e a da informação, ressaltou que a produtividade e o poder nascem desse processamento e transmissão de informações.

Segundo Lazzarato (2014), prevalecem os elementos humanos e não humanos interagindo nos sistemas que conectam homens e máquinas. Assim, a produção de subjetividade acontece com semióticas mistas: significantes e a-significantes. As significantes aparecem direta ou indiretamente, repetida e fragmentada, nos discursos e narrativas da sociedade, enquanto a semiótica a-significante (cálculos matemáticos; algoritmos; indicadores etc.) passam, por exemplo, em processos diagramáticos rotineiros da análise de banco de dados, que permitem múltiplas correlações realizadas por códigos computacionais (algoritmos) para determinar as projeções estatísticas que induzem as tendências comportamentais. Os resultados obtidos nas relações subjetivas de algoritmos determinísticos geram, assim, "verdades absolutas" a serem reforçadas em discursos de poder, que não necessariamente expressam os reais desejos da 
sociedade. Afinal, desejos não poderiam ser modulados em tendências ou modismos, como ressaltam Deleuze e Guattari (1997): “O desejo só emerge quando, seguindo a ruptura de equilíbrios prévios, faz aparecer relações que, de outro modo, não teriam sido possíveis".

Acredita-se que o ciberespaço, por si só, não cumprirá as promessas de liberdade. "Entregue a si mesmo, o ciberespaço torna-se-á uma ferramenta perfeita de controle" (LESSIG, 2006, p.4). Os sistemas educacionais mediados pelas tecnologias e arquiteturas de conteúdo digitais precisam rever sua capacidade inventiva de estimular a produtividade de conhecimento protagonizada pelo aluno, demonstrando disposição para experimentar novas reconfigurações de seus algoritmos envolvidos nos processos de ensino aprendizagem, rejeitando em alguns momentos a criação de mundos preditivos. Métodos e tecnologias educacionais alternativas e que valorizam a experiência da aprendizagem significativa são fundamentais para aproximar o mundo real do virtual.

No Brasil, o ensino híbrido (semipresenciais) já é realidade em algumas instituições que também oferecem a modalidade de EAD com encontros presenciais para interações entre colegas de turma, como alguns cursos de EAD da ESPM - Escola Superior de Propaganda e Marketing; além de recursos de integração, a vivência de projetos reais e da opção de escolha da formação com o currículo flexível, como na metodologia ativa do SENAC - Serviço Nacional de Aprendizagem Comercial. Há também recursos e dispositivos virtuais que permitem maior integração, que estão sendo, cada vez mais, adotados pelas instituições brasileiras, como aponta pesquisa do Censo EAD de 2016 da ABED - Associação Brasileira de Educação a Distância, que aponta os canais mais utilizados, sendo eles, o e-mail, fórum, chat, ferramentas de avisos, avisos automáticos, tutorial em vídeo, videoconferência, SMS e rede social interna.

Esse são exemplos de inciativas que promovem a aproximação entre discentes e docentes, usando espaços abertos nas instituições que incentivam as trocas de saberes e de oportunidades pessoais ou profissionais (bibliotecas e oficinas interativas, colabs ou coworkings). Tori (2010) desta que a convergência entre o virtual e o real na educação (blended learning) se consolida ao explorar as potencialidades de cada aluno, bem como considerar suas limitações, explorando atividades diversificadas. No entanto, soluções criativas de aprendizagem dependem de apoio jurídico, sociocultural, econômico e político para ganharem força de expansão e de constante remodulação. Caso contrário, os sistemas atuais de algoritmos determinísticos, muitas vezes apenas mercadológicos, serão sobrepostos à capacidade do indivíduo de definir sua própria trajetória de aprendizagem contínua e de experiências significativas. 


\section{Aprendizagem significativa com projetos reais em espaços colaborativos}

Para a obtenção de relações mais humanizadas na aprendizagem de forma contínua, com experiência significativa para o aluno Jonassen (2007) acredita que o construtivismo possa ser a teoria que auxilia a dar um novo conceito a EAD mediada pelas novas tecnologias. Salles (2012) em seus estudos alega que a metodologia educacional na EAD deve promover a aprendizagem significativa pautada nas teorias construtivistas com apoio das novas tecnologias da informação e comunicação, de forma que o professor é o mediador desse processo e o aluno construtor do seu conhecimento. A aprendizagem significativa estimula e produz pensamento de qualidade e diversificado, e o aluno não aprende a partir dos professores, mas orientado por ele (SALLES, 2012).

De acordo com Ausubel (1988), a aprendizagem é muito mais significativa à medida que o novo conteúdo é incorporado às estruturas de conhecimento de um aluno e adquire significado para ele a partir da relação com seu conhecimento prévio. Para o autor o conhecimento prévio do aluno é a chave para a aprendizagem significativa, pois quanto mais o indivíduo sabe mais ele aprende. O conteúdo ensinado na escola quando não consegue se ligar a algo conhecido, acontece aprendizagem mecânica e quando as novas informações são aprendidas sem interagir com conceitos relevantes existentes na estrutura cognitiva.

Santos (2009) entende a aprendizagem significativa é mais do que uma acumulação de fatos, é aquela que provoca uma modificação por comportamento do indivíduo, na orientação futura que escolhe, nas atitudes e personalidade. A essa nova aprendizagem que se pode considerar um conceito ou uma proposição ou um modelo mental ou uma imagem, o autor denomina subsunçor ou ideia âncora, que pode ter maior ou menor estabilidade cognitiva. É um processo interativo contribuindo como uma ideia âncora para novos conhecimentos que o aprendiz adquiri. Para Moreira (2008), para que esse processo se efetive, é necessário que exista uma predisposição do aluno para aprender e ao mesmo tempo que o ensino seja potencialmente significativo, com situações planejadas pelo docente que considere a realidade em que o aluno está inserido.

Neste sentido, o que se espera do professor é uma mudança de comportamento que transita de "dar aula" para "construir o conhecimento junto com o aluno". Ronca (1996) questiona: "se o papel do professor é dar aulas, enquanto ele dá a sua aula, o aluno faz o que? " Para ele, essa expressão é fruto do "mundo pronto" que não combina com o movimento contemporâneo que está em constante mudança para um mundo inacabado. 
O aluno precisa ser o protagonista de sua história, de sua aprendizagem e não o telespectador. Para o professor também não se torna interessante "dar aula", pois cansa, frustra e adoece (Ronca, 1996). Cansa porque necessita que cada aluno se mantenha quieto e com foco nele, prestando atenção em algo que não sente necessidade de aprender. $O$ ensino tem que fazer sentido.

O ser humano vive na linguagem e ela é essencial na facilitação da aprendizagem significativa. Para Moreira (2008), as palavras são signos linguísticos e depende-se delas para ensinar qualquer corpo organizado de conhecimentos em situação formal de ensino que é a proposta subjacente à teoria da aprendizagem significativa.

O autor acredita que as atividades colaborativas, presenciais ou virtuais, em pequenos grupos têm grande potencial para facilitar a aprendizagem significativa em função de viabilizar o intercâmbio, a negociação de significados, colocando o professor na posição de mediador.

\section{Produção do conhecimento e o design para a educação mais inovadora}

De acordo com Lévy (1993, p. 17), vive-se uma nova era técnica em que a humanidade se reinventa constantemente. A internet, cada vez mais, está presente nas ações diárias, seja para o trabalho, para o estudo ou para questões pessoais. A cultura digital é uma nova expressão para designar esse novo "estilo de humanidade" (LÉVY, 1993).

Ela se configura por ser novo e que reflete nas atitudes, valores e comportamentos dos indivíduos em todos os tipos de interações mediadas digitalmente - ambientes virtuais variados, blogs, redes sociais, como o Twitter etc.

O conceito de tecnologia é amplo. As tecnologias fazem parte do cotidiano de todas as pessoas, em todas as épocas. Esse conceito não é somente ligado à informática e aos computadores. Segundo Kenski (2003), tecnologia é um conjunto de conhecimentos e princípios científicos que se aplicam ao planejamento, à construção e à utilização de um equipamento em um determinado tipo de atividade.

Os chamados MOOC (Massive Open On-line Course), termo criado por Stephen Downes e George Siemens em 2008 (New Media Consortium, 2013), são grandes repositórios de conteúdo educacional aberto, em geral vídeo-aulas, apostilas e outros materiais multimídia, organizados na forma de cursos. Costumam agregar materiais didáticos de formatos e origens diversas - não necessariamente desenvolvidas para serem trabalhados conjuntamente - provenientes de renomadas instituições de ensino. 
O grande diferencial em relação a cursos on-line convencionais é o conceito de massivo, que muitos alunos podem fazer os cursos simultaneamente, cooperando entre si numa aprendizagem em rede. Cursos tradicionais eram opções equivalentes a seus correspondentes presenciais, mudando-se apenas a mídia. Já os MOOC são exclusivamente on-line, uma vez que não haveria como colocar centenas de milhares de alunos para desenvolverem presencialmente as interações que fazem em rede virtual. Os MOOC estão ainda em processo de evolução. Já incorporaram testes, pontuações, desafios e outras formas de motivar e possibilitar a autoavaliação dos alunos, uma vez que não trabalham com o conceito de tutoria.

O Design Thinking veio somar aos cursos a sua abordagem que catalisa a colaboração, a inovação e a busca por soluções mediante a observação e a cocriação, a partir do conceito de prototipagem rápida e da análise de diferentes realidades.

\section{Considerações Finais}

Ao pesquisar os artigos relacionados a temática desse trabalho pode-se perceber 0 peso da responsabilidade que se coloca na tecnologia para a efetiva Educação a Distância. Porém durante as discussões fica clara a percepção dos autores da não possibilidade de se creditar aos sistemas de aprendizagem a obrigação de ser uma solução infalível para resolver as dificuldades educacionais da contemporaneidade, como uma "tábua de salvação".

Muito se discute também que não se pode ignorar que na educação há avanço das tecnologias e seus espaços midiáticos crescentes que impulsionam a acompanhar, pois caso contrário correrá o risco de desaparecer.

$\mathrm{Na}$ contemporaneidade são muitos os estudos sobre a importância das relações de aprendizagem baseadas em experiências reais e significativas, além do conceito de Design Instrucional como ferramenta para promover ações sistematizadas de ensino em situações didáticas específicas colaborando com a construção e o desenvolvimento do conhecimento real. No entanto, a EAD como área de promoção de estudos possui um grande desafio em como desenvolver a aprendizagem significativa, pois neste entendimento o que precisa ser significativo é o que está, de fato, nas pessoas e não no material. Para isso, será necessário desenvolver e implantar estratégias e ferramentas tecnológicas que favoreçam as relações humanas, incentivando a interação entre colegas, o trabalho em grupo e a troca de experiências e repertório.

É necessário investigar o impacto do ambiente nesta construção de significado, porém 
sem tirar o foco da significação individual e ou coletiva desta ação. Ainda será necessário aprofundar as reflexões sobre o desenvolvimento de novas posturas, novas estratégias e novas formas desta proposta de construção do conhecimento, sobretudo na criação das necessidades e na captação de significados para o discente. $O$ desafio será promove-lo como protagonista neste processo, permitindo que o ambiente virtual também proporcione a aprendizagem significativa, que gere mudanças de comportamentos, colaboração, inovação e soluções mediante observação e cocriação.

\section{Referências}

AUSUBEL, D. P. Aquisição e retenção de conhecimentos: uma perspectiva cognitiva, Lisboa: Editora Plátano, 2003.

Psicologia educativa: um ponto de vista cognoscitivo. México: Trillas, 1988.

ABED - Associação Brasileira de Educação à Distância. Censo EAD 2016: Relatório Analítico da Aprendizagem à distância no Brasil. Disponível em: http://abed.org.br/censoead2016/Censo_EAD_2016_portugues.pdf. Acesso em julho/2018.

BASTOS; CARDOSO; SABBATINI. Uma visão geral da educação à distância.

Disponível em: http://www.edumed.net/cursos/edu002. Acesso em: maio/2005.

BALMANT, O. Conectado para aprender: comunicação a distância. Portal Estadão Edição Especial. Disponível em: https://educacao.estadao.com.br/noticias/geral,conecta do-para-aprender-comunicacao-a-distancia,10000072761. Acesso em julho/2018.

CASTELLS, M. A sociedade em rede. São Paulo: Paz e Terra, v. 1, 1999.

CAVALCANTE C. C.; FILATRO A. Design Thinking, São Paulo: Saraiva, 2016.

DELEUZE, G.; GUATTARI, F. Mil platôs: capitalismo e esquizofrenia. São Paulo: Editora 34, v. 4 e 5, 1997.

JONASSEN, D. Computadores, Ferramentas Cognitivas: desenvolvendo o pensamento crítico nas escolas. Porto-Portugal: Porto Editora. Coleção Ciências da Educação Século $X X I, n^{\circ}$ 23, 2007. 
LAZZARATO, M. Signos, máquinas, subjetividades. São Paulo: Ed. SESC, 2014.

LESSIG, L. Code is law: on liberty in cyberspace. In: Harvard Magazine, jan/2000.

LÉVY, P. A máquina universo: criação, cognição e cultura informática. São Paulo: Artmed, 1998.

LONGO, W. Marketing e comunicação na era pós-digital: as regras mudaram. São Paulo: Hsm do Brasil, 2014.

LAKATOS, E.M.; MARCONI, M.A. Fundamentos de metodologia científica. São Paulo: Atlas, 2010.

MOORE, M. G.; KEARSLEY, G. Educação à distância: sistemas de aprendizagem on line. São Paulo: Cengage, 2014.

PISKURICH, G. M. Tecnologias e ensino presencial e à distância. Campinas: Papirus, 2003.

RONCA, P. C. A prova operatória. São Paulo: Ed. Finep, 1996.

SALLES, C. M. C. A aprendizagem significativa e as novas tecnologias na educação a distância. Dissertação de Mestrado em Administração da Universidade Fundação de Mineração de Educação e Cultura FUMEC. Minas Gerais, p. 6. 2012.

SANTOS, J. C. F. dos. O papel do professor na promoção da aprendizagem significativa. Disponível em: http://juliofurtado.com.br/papeldoprof.pdf. Acesso em: maio/2018.

SOUZA, M. P. R.; SOUZA, D. T. R. Novas tecnologias de comunicação e de informação: o que dizem as revisões acadêmicas canadenses, norte-americanas e a experiência brasileira? Campinas: Educação Temática Digital, v. 9, n. 2, p. 61-79, jun/2008. Disponível em: http://www.fae.unicamp.br/etd/include/getdoc.php?id=133\&article=41\&mode=pdf. Acesso em: ago/2009.

TOFFLER, A. Choque do futuro. Lisboa: Edição Livros do Brasil, 1970.

TORI, R. Educação sem distância. São Paulo: Senac, 2010. 